\title{
Percent Reduction in Transverse Rupture Strength of Metal Matrix Diamond Segments Analysed via Discrete-Element Simulations
}

\author{
Xiuyu Chen ${ }^{1,2}$, Guoqin Huang ${ }^{1,2,3, *}$, Yuanqiang Tan ${ }^{1,2,3}$, Yiqing Yu ${ }^{1,2}$, Hua Guo ${ }^{1,2,3}$ and \\ Xipeng $\mathrm{Xu}^{1,2,3}$ \\ 1 Institute of Manufacturing Engineering, Huaqiao University, Xiamen 361021, China; yu@hqu.edu.cn (X.C.); \\ tanyq@hqu.edu.cn (Y.T.); yyqing@hqu.edu.cn (Y.Y.); guoh1214@hqu.edu.cn (H.G.); xpxu@hqu.edu.cn (X.X.) \\ 2 MOE Engineering Research Center for Machining of Brittle Materials, Huaqiao University, \\ Xiamen 361021, China \\ 3 Fujian Engineering Research Center of Intelligent Manufacturing for Brittle Materials, Fujian 361021, China \\ * Correspondence: smarthgq@hqu.edu.cn; Tel.: +86-592-616-2616; Fax: +86-592-616-2359
}

Received: 25 April 2018; Accepted: 13 June 2018; Published: 20 June 2018

check for updates

\begin{abstract}
The percent TRS reduction, $\mathrm{D}_{\mathrm{TRS}}$, which is the percent reduction of the transverse rupture strength of metal matrix diamond segments with or without diamonds, is a key metric for evaluating the bonding condition of diamonds in a matrix. In this work, we build, calibrate, and verify a discrete-element simulation of a metal matrix diamond segment to obtain $\mathrm{D}_{\mathrm{TRS}}$ for diamond segments with various diamond-grain sizes, concentrations, and distributions. The results indicate that $\mathrm{D}_{\text {TRS }}$ increases with increasing diamond-grain concentration and decreases with increasing diamond-grain size. Both factors can be explained by the total diamond contact length, the increase of which causes the increase in $\mathrm{D}_{\text {TRS }}$. The distribution of diamond grains in segments also strongly influences the increase of $\mathrm{D}_{\text {TRS. The use of }} \mathrm{D}_{\text {TRS }}$ as a metric to assess the bonding condition of diamonds in matrixes is not valid unless the diamond-grain size, concentration, and distribution and total diamond contact length are the same for all diamond segments under consideration.
\end{abstract}

Keywords: diamond segment; transverse rupture strength; discrete-element model; metal matrix; bonding strength

\section{Introduction}

Metal matrix diamond segments are key components for metal matrix diamond tools, which are widely used in industrial applications. A diamond segment is composed of a metal matrix containing diamonds. The main role of the matrix is to bond the diamonds to their segment for as long as possible during use, which is commonly referred to as "diamond retention". The transverse rupture strength (TRS) is an important factor for assessing diamond retention and the wear performance of diamond segments $[1,2]$. In particular, the percent TRS reduction, $\mathrm{D}_{\mathrm{TRS}}$, which represents the percent reduction in TRS between a segment without diamonds and one with diamonds, is used to determine the bonding condition between diamond and metal matrix [2-4].

A large $\mathrm{D}_{\text {TRS }}$ indicates that diamonds are weakly bonded to the matrix. Previous studies experimented with various ingredients for the metal matrix and various diamond coatings [2-5] and found that $\mathrm{D}_{\mathrm{TRS}}$ sometimes changes unexpectedly, although the metal matrix, diamond-grain size, and diamond concentration were the same in each experiment. In other words, $\mathrm{D}_{\mathrm{TRS}}$ becomes unexpectedly invalid during applications. The reason behind this unexpected change is tentatively attributed to the assumption used in deriving $\mathrm{D}_{\mathrm{TRS}}$, that all diamonds in segments are exactly the same 
and uniformly distributed. Although it is true that the diamond distribution in segments is difficult to control with precision, it is not certain whether the diamond-grain distribution does affect $D_{\text {TRS }}$.

In addition to the diamond-grain distribution, the diamond-grain concentration and size have also not been fully studied, and all these factors are difficult to control in experiments. To resolve this difficulty, we use the discrete-element method (DEM) to simulate these systems. Cundall $[6,7]$ first applied the DEM to analyse the behaviour of granular materials and, since then, it has been widely applied to many other materials, such as concrete [8], ceramics [9], and SiC [10]. Thus, in this work, we first build, calibrate, and verify a DEM simulation of a Co-based metal matrix diamond segment, and then analyse the percent TRS reduction of DEM-simulated diamond segments with different diamond-grain concentrations, sizes, and distributions.

\section{Materials and Experimental Details}

\subsection{Fabrication of Diamond Segments}

A Co-based matrix, the composition of which was 70Co-27Cu-3Sn (wt \%), was used as the metal matrix in this work. Diamond grains were purchased from HuangHe Diamond Limited Company, Henan, China. Diamond grains and metal powders of $\mathrm{Co}, \mathrm{Cu}$, and $\mathrm{Sn}$ were mixed and blended for $120 \mathrm{~min}$ via a rotary mixer (SYH01, Chunlai Machinery, Changzhou, China), then poured into a graphite mould, and finally sintered at a temperature of $810{ }^{\circ} \mathrm{C}$ with a hold time of $2 \mathrm{~min}$ and a hold pressure of $15 \mathrm{MPa}$ on an automatic hot-pressing sinter machine (SMVBC, Golden Highway, Zhengzhou, China), which was installed with an infrared sensor (RS-WD-HW-120, Jiandakeren, Shandong, China) for temperature monitoring.

\subsection{The Three-Point Bending Tests and Compression Tests}

Diamond segments with dimensions of $30 \mathrm{~mm} \times 12 \mathrm{~mm} \times 6 \mathrm{~mm}$ were fabricated for three-point bending tests and dimensions of $6 \mathrm{~mm} \times 6 \mathrm{~mm} \times 6 \mathrm{~mm}$ were fabricated for compression tests. The TRS and Young's modulus $(\mathrm{Ec})$ were determined by a three-point bending test in which the bending span was set to $25 \mathrm{~mm}$. The uniaxial compressive strength (UCS) was determined by compression tests. Both tests were performed on an Instron5569 tester (Instron, Boston, MA, USA). For each condition of test, 10 specimens were repeated to obtain the averaged value. A 3D digital microscope (KH8700, HIROX, Tokyo, Japan) was used to observe the fracture failure of the specimen after being tested.

\subsection{Single Grit Shearing Test}

A single grit shear test was carried out on a self-made shear device illustrated in Figure 1. The force was measured by a dynamometer (9265B, Kistler, Jonsered, Switzerland), as shown in Figure 1a. In Figure 1b, the value of $\mathrm{LH}$, which is the distance between the shear point and the bonded level of diamond, was set to $100 \mu \mathrm{m}$ and the shear speed VS was set to $0.5 \mathrm{~mm} / \mathrm{s}$. A shearing force signal shown in Figure 1d shows that the shearing force $\mathrm{F}$ increased linearly at the beginning, dropped slightly when the interfacial debonding occurred, as point A shown in Figure 1d, and then continued to increase to its maximum value when the diamond was rolled out. The critical force, which is the force at the time the interfacial debonding occurred, was used to calibrate the microscopic parameters of the diamond/matrix boundary.

For the calibration of diamond/matrix boundary, the critical force of 10 sintered diamonds with an exposed height $\mathrm{H}$ of $230 \mu \mathrm{m}$ was tested and averaged. To certify the diamond/matrix boundary, the critical force of 10 sintered diamonds with an exposed height $\mathrm{H}$ of $280 \mu \mathrm{m}$ was tested and averaged. 

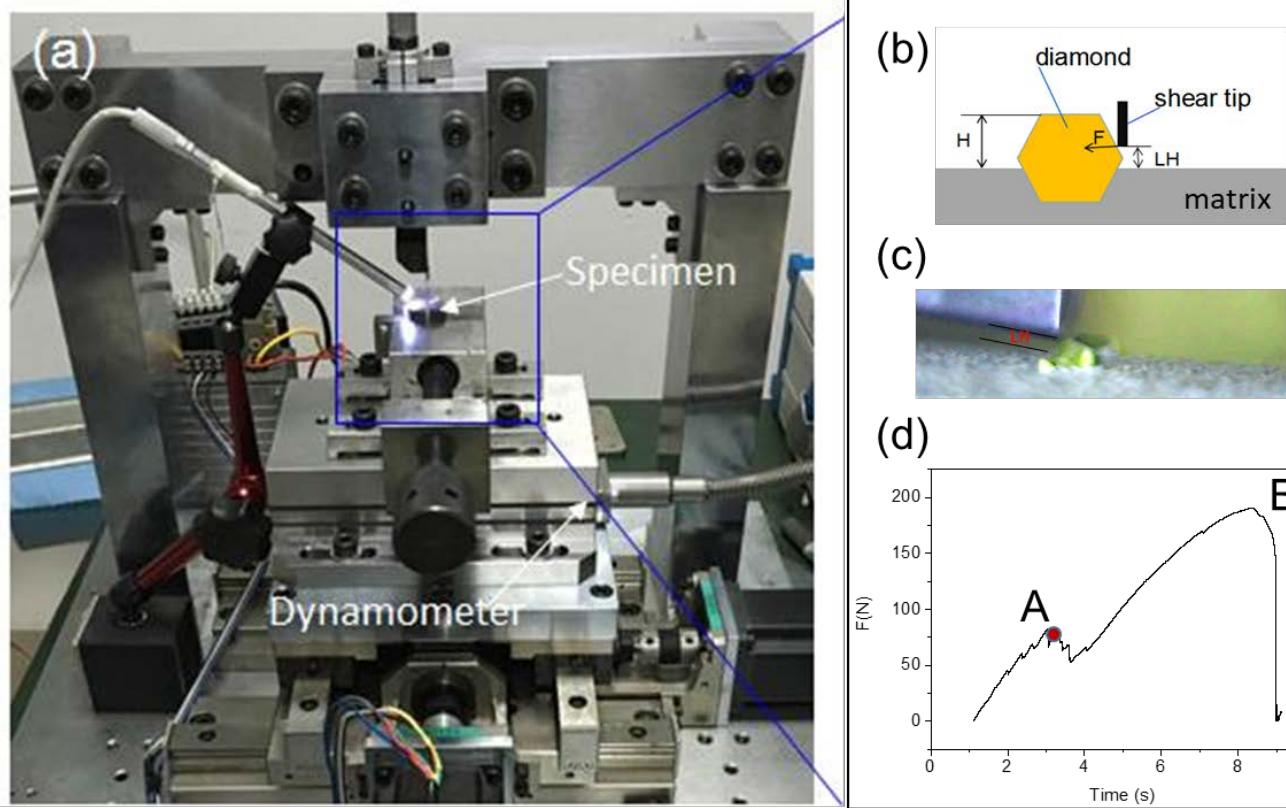

(c)

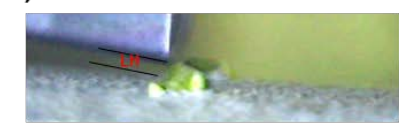

(d)

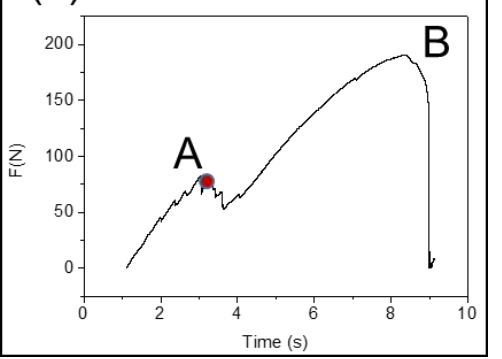

Figure 1. Illustration of shearing test: (a) shearing test device; (b) schematic of shearing; (c) real shearing; (d) shearing force signal.

\section{Establishment, Calibration, and Verification of Discrete-Element Model}

The DEM simulation was implemented by using the software of PFC ${ }^{2 \mathrm{D}}$ (Particle Flow Codes in two dimensions). The DEM model was composed of particles and the bonds between them. In such a model, a contact bond is an interaction between two particles because the particles themselves are deformable, and a parallel bond is an approximation of the physical behaviour of a bond substance between particles [6,11].

A diamond segment consists of a metal matrix and diamond grains, as shown in Figure 2a. Thus, the DEM model of a diamond segment consists of the model of a metal matrix and a model of diamond. The DEM model of the metal matrix is directly represented by spherical particles. The DEM model of the diamond grain is indirectly represented by a hexagonal cluster, which is composed of spherical particles. In other words, the DEM models of the metal matrix and the diamonds should be built individually at first. Then, the model of the diamond grains should be added to the matrix model to form the DEM model of the diamond segment (see Figure $2 b$ ).

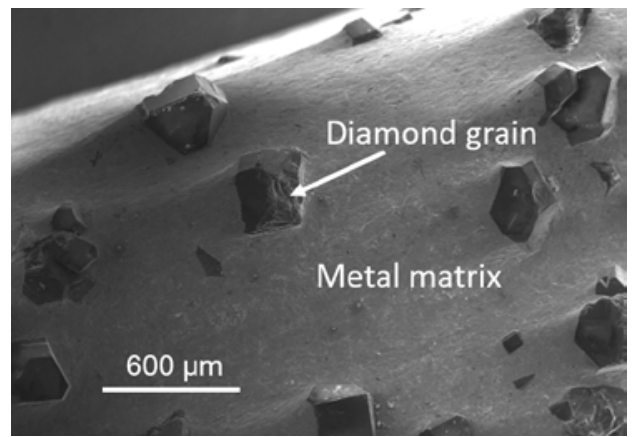

(a)

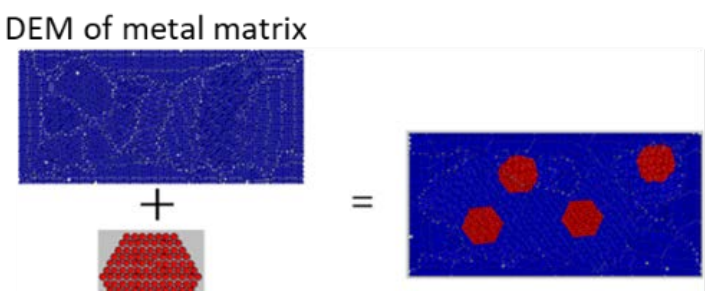

DEM of diamond segment

DEM of diamond

(b)

Figure 2. Illustration of establishing the DEM of a diamond segment: (a) the morgraphy of diamond segment (observed by Scanning Electron Microscope); (b) DEM of a diamond segment. 
In DEM, the microcosmic parameters of the particles in the DEM model directly determine the macrophysical and macromechanical parameters of the DEM simulation. The manner in which these microcosmic parameters are obtained is the premise of the DEM simulation. Reference [12] indicates that they can be calibrated based on a molecular dynamics (MD) simulation, but this is difficult to do for diamond segments because of the scale problem. In fact, a more general calibration methodology is calibrating these parameters by the inversion method, in which the macrocosmic outcome of large-scale DEM simulations is compared with bulk attempts [11,13-15].

Therefore, based on the above analyses, this section details the DEM models for a metal matrix in Section 3.1, for diamonds in Section 3.2, and for diamond segment in Section 3.3. The model of the diamond segment is verified in Section 3.4.

\subsection{Discrete-Element Model of Metal Matrix}

As the Co-based matrix used as the metal matrix in this work was $70 \mathrm{Co}-27 \mathrm{Cu}-3 \mathrm{Sn}$ in wt $\%$, the matrix was composed of $\mathrm{Co}, \mathrm{Cu}$, and $\mathrm{Sn}$ powder particles. Typically, diamond segments are fabricated by hot sintering, which is a solid-liquid process. Because the sintering of the metal matrix diamond segment is also done by pressing sintering, the metal particles are squeezed together. In the DEM of a metal matrix, the particles only represent the skeleton substance, such as $\mathrm{Co}$, whereas the bonding substance, such as $\mathrm{Cu}$ or $\mathrm{Sn}$, is represented by parallel bonds between particles. In this work, the contact bond was also used in the matrix model to describe the elasticity of the metal matrix. Thus, two types of bonds existed in the DEM of the Co-based matrix used in this work, as shown in Figure 3: the $\mathrm{Co}-\mathrm{Co}$ bond 1 is a parallel bond, and the Co-Co bond 2 is a contact bond.

(a)

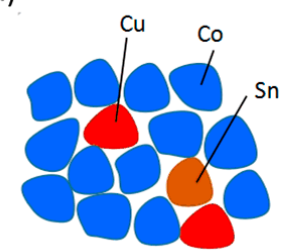

(b)

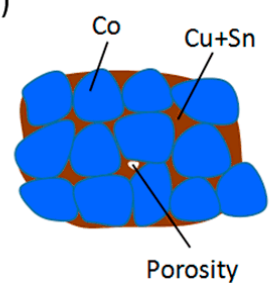

(c)

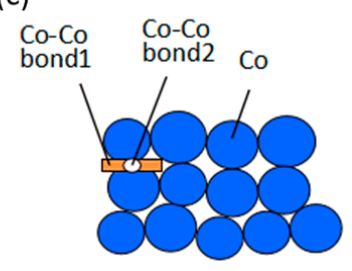

Figure 3. Illustration of Co-Cu-Sn-based metal matrix: (a) before sintering, (b) after sintering, and (c) DEM Co-Cu-Sn metal matrix.

To invert the microscopic parameters of the metal matrix, the three-point bending test and compression test were calculated by using the DEM model. The simulated TRS, UCS, and Ec were compared with the corresponding experimental results, the experimental details of which are presented in Section 2. When the simulated results match the experimental results with an error of less $10 \%$, the microcosmic parameters of the Co-based metal matrix DEM model were calibrated. The matching results are listed in Table 1 . Figure 4 also shows the comparison of segment failure by ways of experiment and simulation. It can be seen that the features of fracture failure by experiment were identical to that by simulation.

Table 1. Values of UCS, Ec, and TRS of metal matrix obtained by experiment and DEM simulation.

\begin{tabular}{cccc}
\hline \multirow{2}{*}{ Mechanical Properties } & \multicolumn{2}{c}{ Co-Based Metal Matrix (Segment without Diamonds) } \\
\cline { 2 - 4 } & Experimental Results & Simulation Results & Error \\
\hline UCS/MPa & 1681 & 1842 & $9.6 \%$ \\
Ec/GPa & 13.8 & 12.8 & $7.2 \%$ \\
TRS/MPa & 1120 & 1046 & $4.2 \%$ \\
\hline
\end{tabular}


(a)

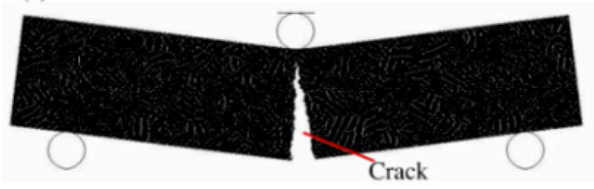

(b)

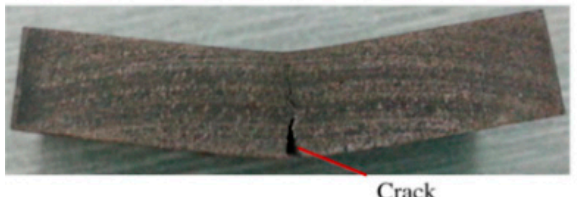

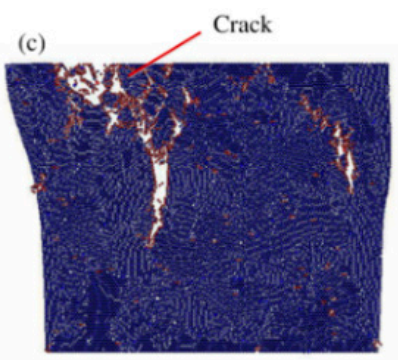

(d)

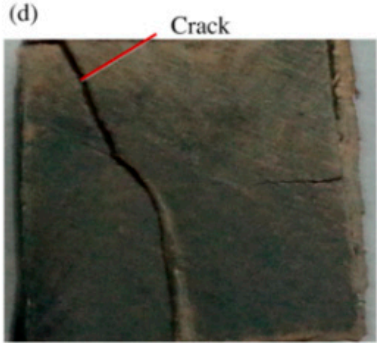

Figure 4. Failure of Co-based metal matrix after being tested: $(\mathbf{a}, \mathbf{c})$ by DEM simulation; $(\mathbf{b}, \mathbf{d})$ by experiment.

\subsection{Discrete-Element Model of Diamond}

Due the hexagonal shape of diamonds, the DEM of a diamond grain is built by a cluster of particles bonded in hexagonal shape. The particle size here was $0.023 \mathrm{~mm}$. As a diamond is a typical brittle material, only the parallel bond was used in the model to constrain the particles [8-10]. The microcosmic parameters of the diamond model were inverted by a uniaxial compression test, as shown in Figure 5. The values of Young's Ec, Poisson's ratio $\gamma$, and the UCS obtained by simulation were compared with the corresponding values from [15], as summarized in Table 2.

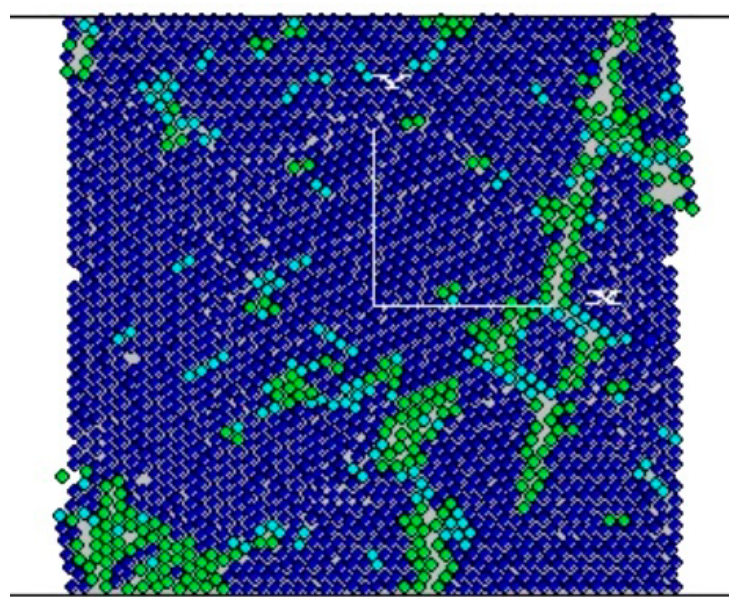

Figure 5. Compression test simulation of the diamond model.

Table 2. Main mechanical properties of the diamond obtained by the DEM simulation and ref. [15].

\begin{tabular}{ccc}
\hline Mechanical Properties & Values from [16] & Values Simulated by DEM Model \\
\hline Young's modulus Ec (GPa) & $900-1000$ & 940 \\
Poisson's ratio $\gamma$ & $0.069-0.12$ & 0.095 \\
UCS (MPa) & $4500-5800$ & 4853 \\
\hline
\end{tabular}




\subsection{Discrete-Element Model of the Diamond Segment}

The DEM of a diamond segment was built by adding the diamonds' DEM to the DEM of the metal matrix and then adding bonds to constrain the diamonds and the matrix into a block. The bond between the diamond and the matrix is called as diamond/matrix boundary. As the diamond segment is a brittle composite material with a certain elasticity, both the parallel and contact bonds were combined to describe the bonding condition of the diamond/matrix boundary.

Besides the microscopic parameters of DEMs of the matrix and diamond, the microscopic parameters also need to be calibrated. In this work, the microscopic parameters of the diamond/matrix boundary bond were calibrated by single diamond shear testing. The experiment condition is detailed in Section 2. The calibration was done in three steps as follows:

Step 1: A DEM model of the Co-based metal matrix diamond segment was made. The values of the parameters for the metal matrix and diamond were set according to the results of calibrations in Sections 3.1 and 3.2. The initial values of the parameters of the diamond/matrix boundary were then assigned.

Step 2: The shearing test in the DEM was simulated, as shown in Figure 6, in which the exposure height $\mathrm{H}$ was set as $230 \mu \mathrm{m}$. Comparing the simulated critical force with the experimental critical force, when the simulation result matched the experimental result with an error of less $10 \%$, as shown in Table 3, the microcosmic parameters of the diamond/matrix boundary were inverted.

Step 3: After inverting the microscopic parameters, the exposure height $\mathrm{H}$ of $280 \mu \mathrm{m}$ was used to verify the accuracy of the diamond/matrix boundary's microcosmic parameters. The shear force by simulation and experiment are also compared in Table 3.

(a)

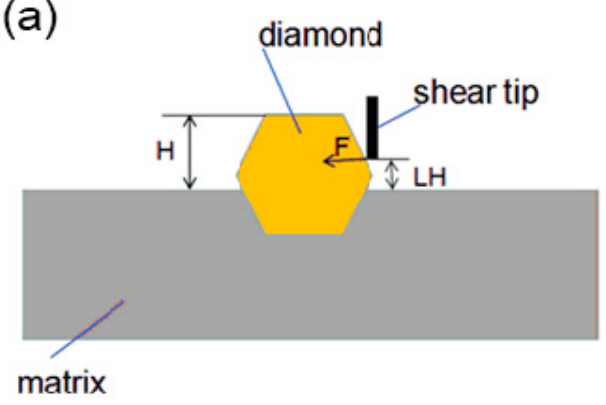

(b)

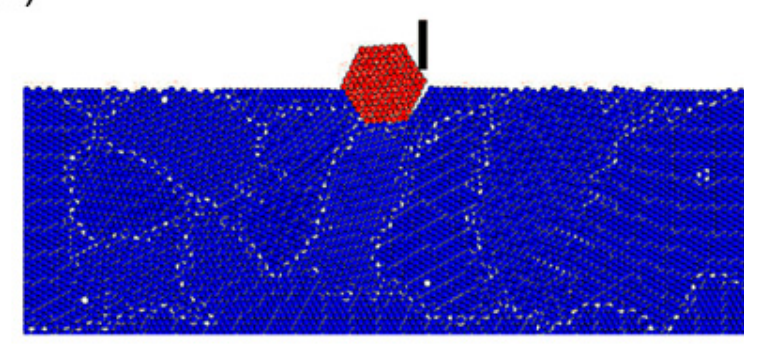

Figure 6. Single diamond shearing test: (a) schematic diagram; (b) simulation by DEM.

Table 3. Critical force of diamond obtained by experiment and DEM simulations.

\begin{tabular}{|c|c|c|c|}
\hline \multirow{2}{*}{ Exposure Height ( $\mu \mathrm{m})$} & \multicolumn{2}{|c|}{ Critical Force of Shearing Test, F (N) } & \multirow{2}{*}{$\begin{array}{c}\text { Error } \\
(\%)\end{array}$} \\
\hline & By Experiment (N) & By Simulation (N) & \\
\hline 230 & 70.5 & 71.1 & 0.9 \\
\hline 280 & 67.3 & 68 & 1.0 \\
\hline
\end{tabular}

\subsection{Verification of Discrete-Element Model of the Diamond Segment}

Based on the above work, the DEM of the diamond segment was built and all of its microscopic parameters were calibrated, which are summarized in Table 4.

To verify the validity of the diamond segment's DEM, a three-point bending test was carried out. Here, diamond grains with a size of $550 \mu \mathrm{m}$ (30/40 US mesh) and a concentration of $50 \%$ were used. It should be noted that in the diamond industry, the $25 \%$ volume of diamonds by $\mathrm{cm}^{3}$ or $0.88 \mathrm{~g}$ (4.4 Carat) of diamonds by $\mathrm{cm}^{3}$ is defined as the $100 \%$ concentration of diamonds in the segment [17]. The TRS obtained by simulation and experiment are compared in Table 5, the error of which is within the satisfactory value of less $10 \%$. 
Table 4. The values of microcosmic parameters of the diamond segment.

\begin{tabular}{lccc}
\hline & \multicolumn{3}{c}{ Values of Microcosmic Parameters } \\
\cline { 2 - 4 } & Matrix & Diamond & Diamond/Matrix Boundary \\
\hline Particle density $\left(\mathrm{kg} / \mathrm{m}^{3}\right)$ & 8900 & 3500 & $/$ \\
Particle contactmodulus, Ec (GPa) & $1.3 \times \mathrm{e}^{10}$ & $3 \times \mathrm{e}^{11}$ & $/$ \\
Particle stiffnessratio, kn/ks & 1 & 1 & $/$ \\
Particle friction coefficient & 0.8 & 0.1 & $/$ \\
Isotropics Stress, (Pa) & $-2.0 \times \mathrm{e}^{7}$ & $-5.0 \times \mathrm{e}^{7}$ & 1 \\
Radius multiplier of parallel bond & 1 & 1 & $4 \times \mathrm{e}^{7}$ \\
Elasticity modulus of parallel bond (Pa) & $1.3 \times \mathrm{e}^{9}$ & $11 \times \mathrm{e}^{11}$ & $4 \times \mathrm{e}^{3}$ \\
Normal strength of parallel bond (Pa) & $3 \times \mathrm{e}^{8}$ & $1 \times \mathrm{e}^{10}$ & $4 \times \mathrm{e}^{3}$ \\
Shear strength of parallel bond (Pa) & $3 \times \mathrm{e}^{8}$ & $1 \times \mathrm{e}^{10}$ & $5 \times \mathrm{e}^{3}$ \\
Normal strength of contact bond (Pa) & $6 \times \mathrm{e}^{7}$ & $/$ & $5 \times \mathrm{e}^{3}$ \\
Shear strength of contact bond (Pa) & $6 \times \mathrm{e}^{7}$ & $/$ & \\
\hline
\end{tabular}

Table 5. TRS of the diamond segment: results of experiment and DEM simulations.

\begin{tabular}{ccccccccc}
\hline \multirow{2}{*}{$\begin{array}{c}\text { Diamond Size } \\
\text { (US Mesh) }\end{array}$} & $\begin{array}{c}\text { Concentration } \\
(\mathbf{\%})\end{array}$ & $\begin{array}{c}\text { Simulation } \\
\mathbf{( M P a )}\end{array}$ & $\begin{array}{c}\text { Experiment } \\
\mathbf{( M P a )}\end{array}$ & $\begin{array}{c}\text { Error } \\
\mathbf{( \% )}\end{array}$ & $\begin{array}{c}\text { Simulation } \\
\mathbf{( N )}\end{array}$ & $\begin{array}{c}\text { Experiment } \\
(\mathbf{N})\end{array}$ & $\begin{array}{c}\text { Error } \\
\mathbf{( \% )}\end{array}$ \\
\hline $30 / 40$ & 50 & 743 & 786 & 5.5 & 17.4 & 15.9 & 9.4 \\
\hline
\end{tabular}

\section{Simulation of Percent Reduction of TRS}

The percent TRS reduction, $\mathrm{D}_{\text {TRS }}$, is generally used to describe the retention ability of diamonds in diamond segments. Thus, the $\mathrm{D}_{\mathrm{TRS}}$ was calculated by: $\mathrm{D}_{\mathrm{TRS}}=\left(\sigma_{0}-\sigma\right) / \sigma_{0} \times 100 \%$, where $\sigma_{0}$ is the TRS of the metal matrix and $\sigma$ is the TRS of the diamond segment with diamonds.

For a diamond segment with different ingredients under the same sintering conditions, when the concentration and the sizes of the diamonds in the segment were kept the same, a smaller $D_{\text {TRS }}$ equated to a generally stronger diamond retention [18]. In order to study the feasibility of this approach, the DEM model with the microcosmic parameters obtained from Section 4 was applied to study the factors that influence the $\mathrm{D}_{\mathrm{TRS}}$. To do this, $\mathrm{D}_{\mathrm{TRS}}$ was calculated by the DEM simulation in which diamond concentration, diamond size, and diamond distribution were varied. In this section, the dimension of the segment's DEM model was $30 \mathrm{~mm} \times 6 \mathrm{~mm}$.

\subsection{Effect of Diamond Concentration}

To determine how diamond concentration affects $\mathrm{D}_{\mathrm{TRS}}$, diamonds were added to the Co-based matrix with concentrations of $25 \%, 50 \%, 75 \%$, and $100 \%$. The simulated $\mathrm{D}_{\text {TRS }}$ are plotted in Figure 7 . It can be found that the $\mathrm{D}_{\text {TRS }}$ increases with increasing diamond concentration.

As the dimension of the segment's DEM was $30 \mathrm{~mm} \times 6 \mathrm{~mm}$ for the four concentrations above, their corresponding diamond weights were $0.36,0.72,108$, and $1.44 \mathrm{carat} / \mathrm{cm}^{3}$, and the number of diamond grains were $43,88,129$, and 172 . As a typical of composite material, diamonds can be considered as a heterogeneous material to the matrix. Due to the DEM simulation in this work being in 2D mode, the total diamond contact length was used to quantitate the contacting boundary of the diamonds in the matrix. As the diamond-grain size was $550 \mu \mathrm{m}$, the total diamond contact length $\mathrm{L}_{\text {total }}$ for the four concentrations were 77, 154, 231, and $308 \mathrm{~mm}$, respectively. The relationship between $\mathrm{D}_{\text {TRS }}$ and $\mathrm{L}_{\text {total }}$ is presented in Figure 7. It can be easily concluded that $\mathrm{D}_{\text {TRS }}$ increases nearly linearly with $\mathrm{L}_{\text {total }}$. 


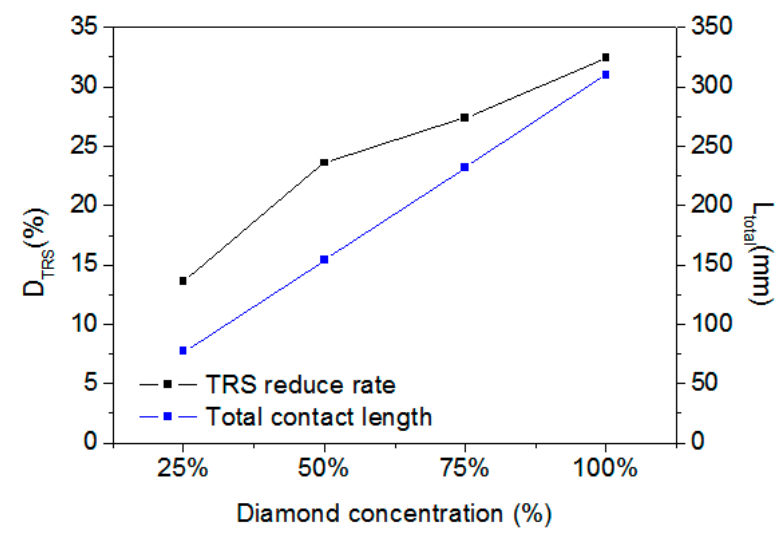

Figure 7. $\mathrm{D}_{\mathrm{TRS}}$ and total diamond contact length $\mathrm{L}_{\text {total }}$ versus diamond concentration.

\subsection{Effect of Diamond-Grain Size}

To determine the effect of diamond-grain size, diamond segments with the same grain concentration of $25 \%$ but with different diamond-grain sizes of $550 \mu \mathrm{m}$ (30 US mesh), $380 \mu \mathrm{m}$ (40 US mesh), and $270 \mu \mathrm{m}$ (50 US mesh) were simulated. Figure 8 presents the $\mathrm{D}_{\text {TRS }}$ and $\mathrm{L}_{\text {total }}$ versus the increase of diamond-grain size. Figure 8 also shows that, with the same grain concentration, $\mathrm{D}_{\text {TRS }}$ decreases with increasing diamond size.

As the dimension of the segment was $30 \mathrm{~mm} \times 6 \mathrm{~mm}$, the number of diamond grains was 44, 92, and 180 , and $\mathrm{L}_{\text {total }}$ were 77,110 , and $150 \mathrm{~mm}$, respectively, for the three types of diamond segments. It can be found that with the same diamond-grain concentration, the number of diamond grains and $\mathrm{L}_{\text {total }}$ in the DEM model depend on the diamond-grain size. From Figure 8, it also can be found that $\mathrm{D}_{\text {TRS }}$ increases linearly with total contact length, which agrees with the result shown in Figure 7.

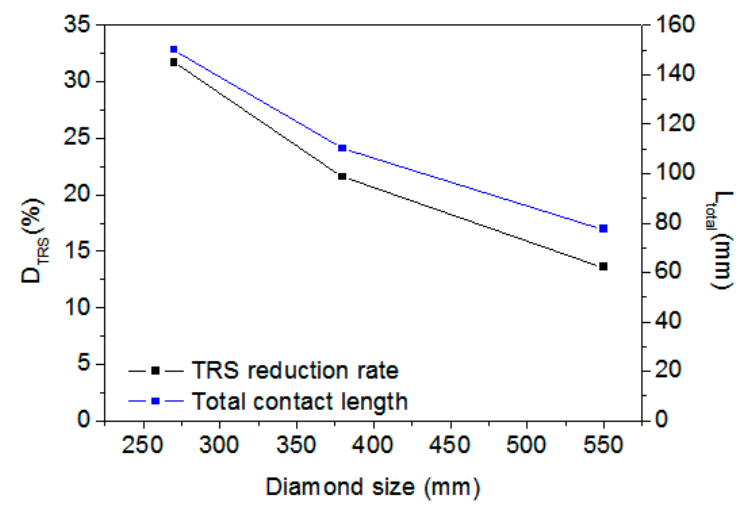

Figure 8. Percent TRS reduction $\mathrm{D}_{\text {TRS }}$ and total diamond boundary length $\mathrm{L}_{\text {total }}$ versus diamond size.

To further check the effect of grain size, four diamond segments were designed with the same total contact length. This was done by using the same total number of diamond grains and the same diamond distribution, but with different diamond-grain sizes, as listed in Table 6. The total contact length was set as $110 \mathrm{~mm}$, and the total number of diamonds was set as 92 . Then, the diamond-grain concentrations were calculated to be $25 \%, 29.7 \%, 29.7 \%$, and $32 \%$ for segments S1-S4, respectively (see Table 6).

Next, $D_{\text {TRS }}$ was calculated for the four segments (Figure 9 and Table 6). Ordering the segments from smallest $\mathrm{D}_{\mathrm{TRS}}$ to largest gives $\mathrm{S} 1<\mathrm{S} 2=\mathrm{S} 3<\mathrm{S} 4$. Based on Table 6, ordering the segments from smallest diamond-grain concentration to largest gives the same result: $\mathrm{S} 1<\mathrm{S} 2=\mathrm{S} 3<\mathrm{S} 4$. By comparing these two ordered lists, it can be concluded that: (i) $D_{\text {TRS }}$ generally increases with increasing grain concentration, which is consistent with the result discussed in the Section 3.1; and (ii) for the same $\mathrm{L}_{\text {total }}$ 
and diamond-grain concentration, $\mathrm{D}_{\mathrm{TRS}}$ is independent of diamond-grain size. The diamond-grain concentration and total contact length of diamonds strongly impact the $\mathrm{D}_{\text {TRS }}$. The total contact length of the diamonds corresponds with the contact surface area between the diamond grains and the matrix in actual three-dimensional diamond segments. It is reasonable that with the increase of diamonds in the matrix, the TRS reduction increases.

Table 6. Properties of diamond segments with the given number of diamonds of the given grain size.

\begin{tabular}{|c|c|c|c|c|c|c|}
\hline \multirow{2}{*}{$\begin{array}{l}\text { Diamond } \\
\text { Segments }\end{array}$} & \multicolumn{3}{|c|}{ Number of Diamonds with Given Grain Size } & \multirow{2}{*}{$\begin{array}{l}\text { Total Contact Length } \\
(\mathrm{mm})\end{array}$} & \multirow{2}{*}{$\begin{array}{l}\text { Diamond Concentration } \\
(\%)\end{array}$} & \multirow{2}{*}{$\mathrm{D}_{\mathrm{TRS}}(\%)$} \\
\hline & $550 \mu \mathrm{m}$ & $380 \mu \mathrm{m}$ & $270 \mu \mathrm{m}$ & & & \\
\hline S1 & 0 & 92 & 0 & 110 & 25 & 21.6 \\
\hline S2 & 29 & 31 & 32 & 110 & 29.7 & 22.0 \\
\hline S3 & 23 & 32 & 37 & 110 & 29.7 & 22.0 \\
\hline S4 & 43 & 0 & 49 & 110 & 32 & 22.8 \\
\hline
\end{tabular}

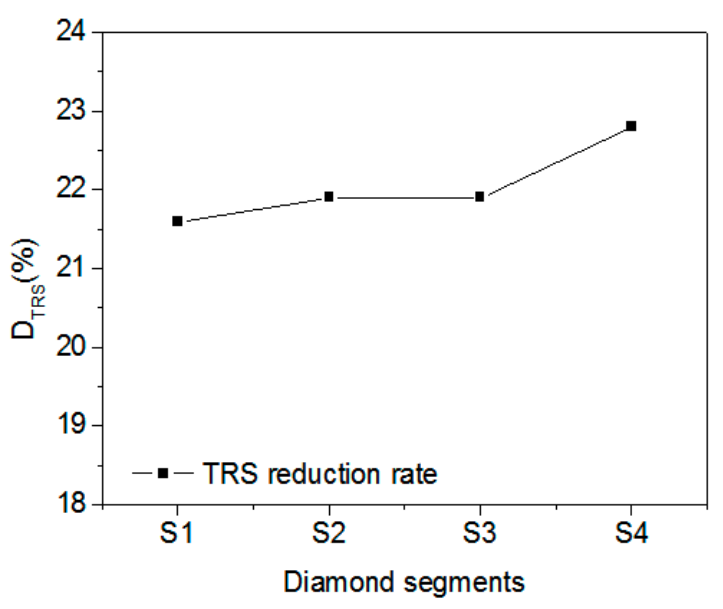

Figure 9. Percent TRS reduction for the various diamond segments (see Table 6).

\subsection{Effect of Diamond Distribution}

To investigate the effect of diamond-grain distribution with the same diamond-grain concentration and diamond-grain size, segments with four diamond-grain distributions were designed, which are shown in Figure 10. To avoid the effect of diamond-grain size, diamond-grain concentration, and total contact length on $\mathrm{D}_{\mathrm{TRS}}$, in the Figure 10, the diamond particle size was $550 \mu \mathrm{m}$ and the concentration was $50 \%$ (with 90 diamonds in each segment) for all four samples. The four distributions are based on the following considerations:
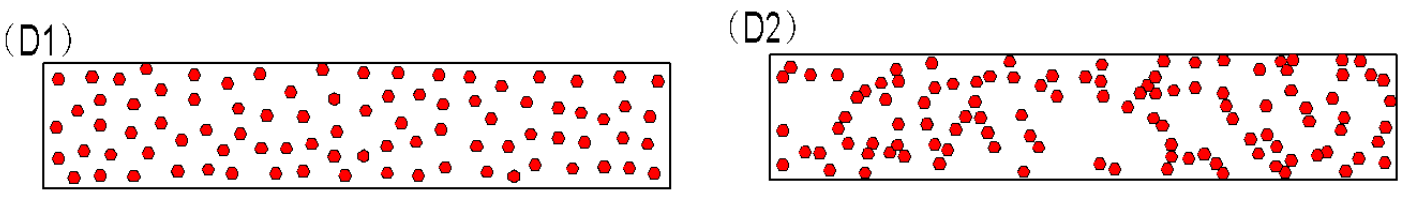

(D3)

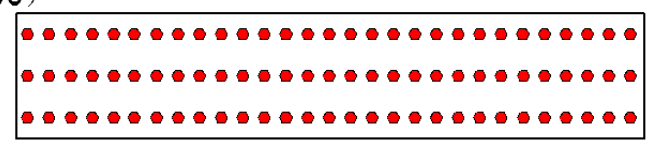

(D4)

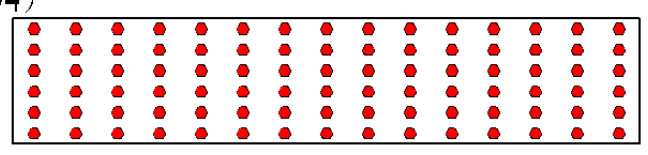

Figure 10. Diamond distributions D1-D4. See text for details.

(1) As described in the introduction, a uniform distribution presupposes using the percent TRS reduction to assess diamond retention. Thus, distribution D1 is a uniform distribution. 
(2) In real sintered diamond tools, diamonds are distributed by mixing diamond grains with metal matrix powders in a rotary machine before sintering. In theory, diamonds can be uniformly distributed given sufficient mixing time. However, diamonds are distributed with a random distribution and some even reunite, as shown in Figure 2a. We set six random distributions for diamonds in a segment, as shown in Figure A1 in Appendix A. From Figure A2 in Appendix A, it shows that the different distributions correspond to different $\mathrm{D}_{\mathrm{TRS}}$. Thus, distribution $\mathrm{D} 2$ is a random distribution, which is the same as the distribution (a) in Figure A1 in Appendix A.

(3) For the sake of comparison, two ordered distributions D3 and D4 were designed. D3 has three rows, and D4 has six rows (the number and the size of the diamonds in D3 and D4 are the same).

The TRS of the matrix, which is without diamonds, is $1046 \mathrm{MPa}$, as shown in Table 1, and the results for $\mathrm{D}_{\mathrm{TRS}}$ of the segments with the different diamond-grain distributions are listed and compared in Table 7. The $5.1 \%$ difference in $\mathrm{D}_{\mathrm{TRS}}$ of distributions D1 and D2 is caused by the spatial difference in distributions D1 and D2. For the ordered distributions, the difference of $18 \%$ between $\mathrm{D}_{\mathrm{TRS}}$ for D3 and D4 is caused by changing the number of rows from three to six. It can be concluded that the diamond-grain distribution is also a key factor determining the $\mathrm{D}_{\mathrm{TRS}}$.

Table 7. Percent TRS reduction for different diamond distributions.

\begin{tabular}{ccc}
\hline Diamond Distribution & TRS (MPa) & Percent TRS Reduction (\%) \\
\hline D1 & 788 & 24.7 \\
D2 & 734 & 29.8 \\
D3 & 729 & 30.3 \\
D4 & 916 & 12.3 \\
\hline
\end{tabular}

The comparison between D3 and D4 indicates that different orderly arrangements also have a significant effect on the TRS reduction rate. When the number of rows changed from three to six, the TRS reduction rate changed from $12.3 \%$ to $30.3 \%$. In order to study the effect further, two more kinds of ordered distributions were taken into account, as shown in Figure 11 (which is the same as Figure 10, in which the dimension segment was $30 \mathrm{~mm} \times 6 \mathrm{~mm}$, the diamond size was $550 \mu \mathrm{m}$, and the number of diamonds in each segment was 90). The distances of two diamonds were different: V1-V4 in Figure 11 were $2 \mathrm{~mm}, 1.5 \mathrm{~mm}, 1.2 \mathrm{~mm}$, and $1 \mathrm{~mm}$, respectively; H1-H4 were $1.04 \mathrm{~mm}, 1.36 \mathrm{~mm}$, $1.67 \mathrm{~mm}$, and $2 \mathrm{~mm}$, respectively; and L1-L4 were $1 \mathrm{~mm}, 0.75 \mathrm{~mm}, 0.6 \mathrm{~mm}$, and $0.5 \mathrm{~mm}$, respectively.

The effects of the row's number and horizontal distance on $\mathrm{D}_{\mathrm{TRS}}$ are presented in Figure 12. It can be seen that the $\mathrm{D}_{\text {TRS }}$ decreased with the increase of either row's number or the horizontal distance.

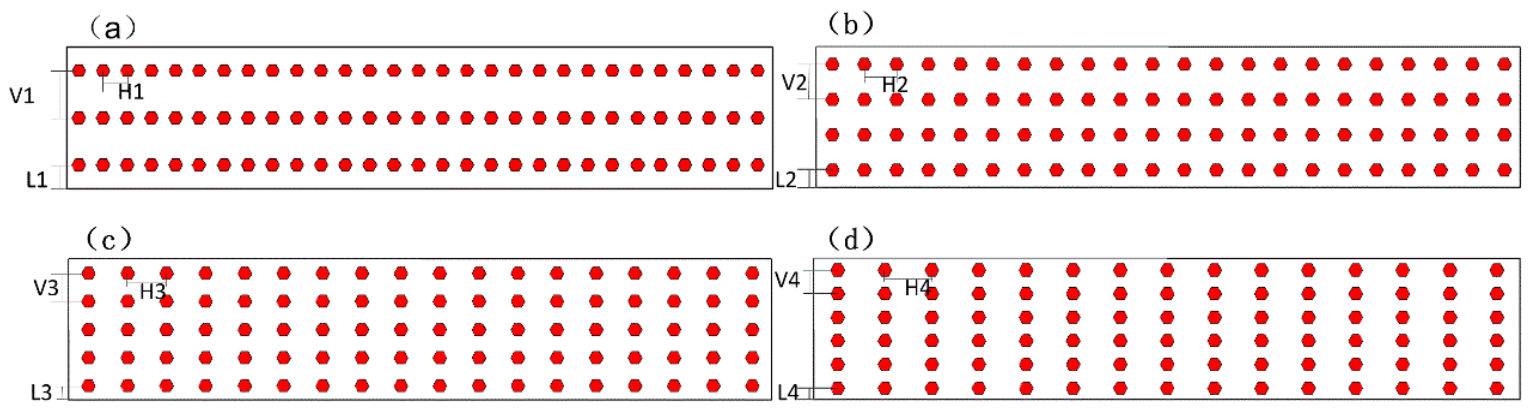

Figure 11. Different order distributions of diamonds in the segment: three rows (a), four rows (b), five rows $(\mathbf{c})$, and six rows $(\mathbf{d})$. 


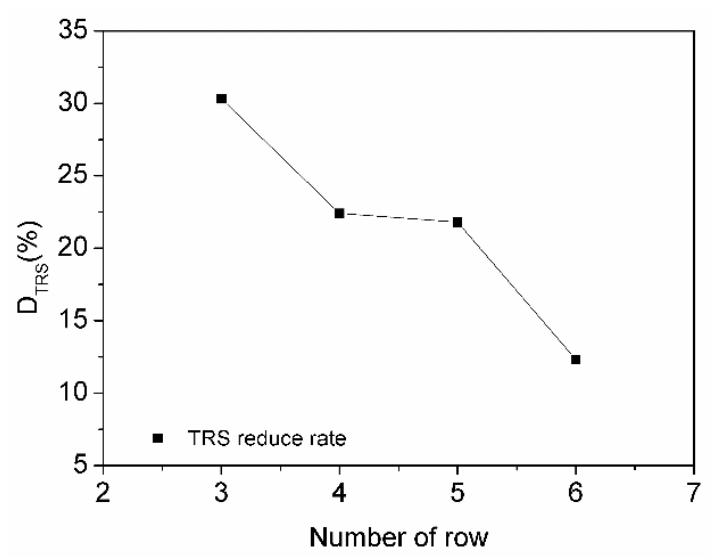

(a)

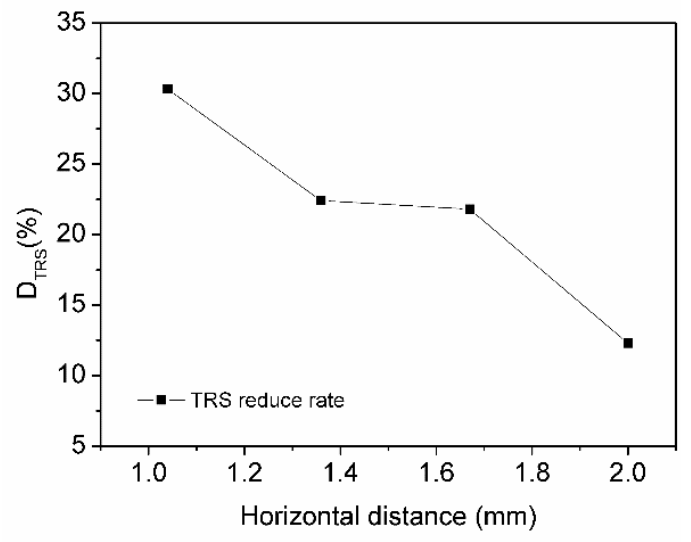

(b)

Figure 12. Order distribution versus reduction rate of TRS. (a) Effect of row number; (b) effect of horizontal distance.

L1-L4 is the distance from specimen edge to the nearest diamond in distributions (a-d) in Figure 11. L1 is the greatest and L4 is the least in L1-L4. The bond of the matrix/diamond boundary is weaker than the bond of the matrix/matrix. According to the features of the composite material, the closer the weak bond is to the edge, the easier it is for the material to be destroyed. However, from Figure 12, we can see the $\mathrm{D}_{\text {TRS }}$ of the segment with three rows is larger than the segment with six rows, which means that the $\mathrm{D}_{\text {TRS }}$ of the segment with L1 $(1 \mathrm{~mm})$ is larger than the segment with L4 $(0.5 \mathrm{~mm})$, and the segment with L1 is easier to be destroyed. Thus, we can find that the distance from the specimen edge to the nearest diamond interface has less affect than the distance of the changed horizontal direction.

\subsection{Discussion}

These simulation results led us to conclude that the diamond-grain size, concentration, and distribution in segments strongly affect the percent of TRS reduction.

However, note that all of the above simulations were implemented by DEM with the same matrix and the same diamond-matrix bonding conditions because all the microscopic parameters in the DEM models for the metal matrix, diamond clusters, and diamond segments were fixed after being calibrated. In other words, the differences obtained for $\mathrm{D}_{\text {TRS }}$ in Sections 4.1-4.3 were induced only by the different diamond distributions, rather than by the diamond bonding conditions with the matrix. This observation can reasonably explain the unexpected change in $\mathrm{D}_{\text {TRS }}$ while evaluating the diamond bonding condition by TRS. Therefore, $\mathrm{D}_{\text {TRS }}$ is not a reasonable metric to evaluate the bonding condition of diamonds in segments unless the grain size, concentration, and distribution of diamonds in the segments are the exactly same.

\section{Conclusions}

The major factors affecting the percent of TRS reduction, $\mathrm{D}_{\mathrm{TRS}}$, of diamond segments are the diamond-grain size, concentration, and distribution within the diamond segment. These factors were analysed by DEM simulation, which also considered the diamond total contact length $\mathrm{L}_{\text {total }}$ to explain the results.

The results show that $\mathrm{D}_{\mathrm{TRS}}$ for diamond segments increases with diamond-grain concentration but decreases with diamond-grain size. The percent of TRS reduction increases with the increase of the $\mathrm{L}_{\text {total }}$ in the segment. For a given $\mathrm{L}_{\text {total }}$, diamond-grain concentration, and diamond-grain distribution, the diamond grains of differing sizes have no effect on $\mathrm{D}_{\text {TRS }}$. However, the spatial distribution of the diamond grains with the segment strongly affects the $\mathrm{D}_{\text {TRS }}$. Finally, the $\mathrm{D}_{\text {TRS }}$ is not a reasonable 
metric for evaluating the bonding conditions of diamonds in segments unless the diamond-grain size, concentration, and distribution are the same in all segments under consideration.

Author Contributions: X.X. and G.H. conceived and designed the study, H.G. and G.H. designed the experiments, X.C. performed the experiments and DEM simulations. X.C., G.H. and Y.Y. analyzed the data. X.X., H.G. and Y.T. contributed reagents/materials/analysis tools. X.C. wrote the paper. G.H., Y.T., X.C., H.G., Y.Y. and X.X. revised the paper.

Funding: This research was funded by the National Natural Science Foundation of China (Grant Nos. 51575197 and 11772135), Program for Changjiang Scholars and Innovative Research Team in University of China (Grant No. IRT_17R41), Program for New Century Excellent Talents in Fujian Province University and Natural Science Foundation of Fujian Province in China (Grant No. 2017H0023).

Conflicts of Interest: The authors declare no conflict of interest.

\section{Appendix A}
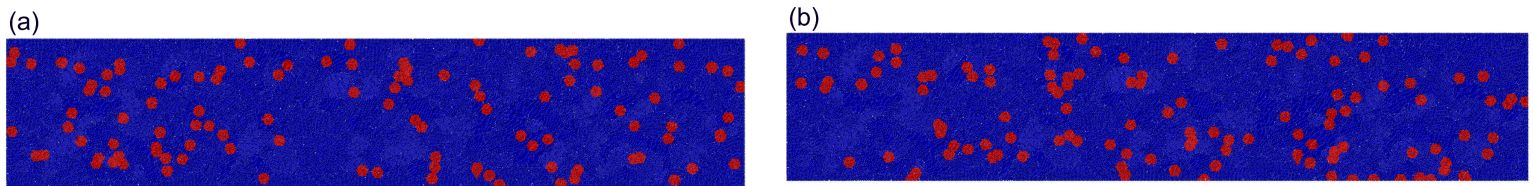

(c)

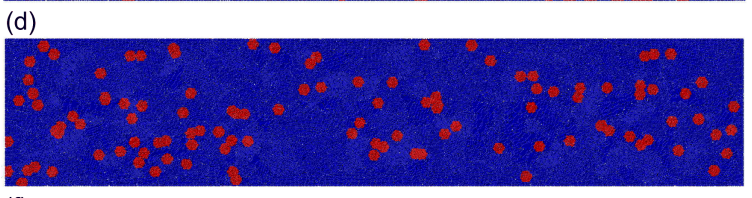

(e)

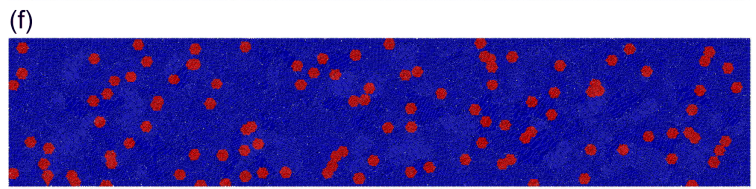

Figure A1. Six different random distributions of diamond in segment.

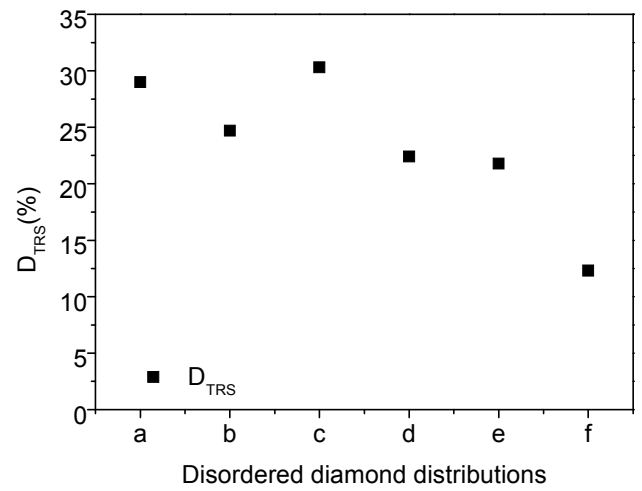

Figure A2. Disorderly distribution VS reduce rate of TRS.

\section{References}

1. Abyzov, A.M.; Shakhov, F.M.; Averkin, A.I.; Nikolaev, V.I. Mechanical properties of a diamond-Copper composite with high thermal conductivity. Mater. Des. 2015, 87, 527-539. [CrossRef]

2. Oliveiral, F.A.C.; Anjinho, C.A.; Coelho, A. PM materials selection: The key for improvedperformance of diamond tools. Met. Powder Rep. 2017, 72, 339-344. [CrossRef]

3. Yu, Y.Q.; Xu, X.P. Improvement on the performance of diamond segments for rock sawing, part 1: Effects of segment components. Key Eng. Mater. 2003, 250, 46-53. [CrossRef]

4. Xu, X.P.; Tie, X.R.; Wu, H.R. The effects of a Ti coating on the performance of metal-bonded diamond composites containing rare earth. Int. J. Refract. Met. Hard Mater. 2007, 25, 244-249. [CrossRef] 
5. Dai, Q.L.; Luo, C.B.; Xu, X.P.; Wang, Y.C. Effects of rare earth and sintering temperature on the transverse rupture strength of Fe-based diamond composites. J. Mater. Process. Technol. 2002, 129, 427-430. [CrossRef]

6. Cundall, P.A. A computer model for simulating progressive large scale movements in blocky rock systems. Proc. Int. Symp. Rock Fract. 1971, 2, 129-136.

7. Cundall, P.A.; Strack, O.D.L. Discrete numerical model for granular assemblies. Geothechnique 1979, $29,47-65$. [CrossRef]

8. Hunt, S.P.; Meyers, A.G.; Louchnikov, V. Modelling the Kaiser effect and deformation rate analysis in sandstone using the discrete element method. Comput. Geotech. 2006, 30, 611-621. [CrossRef]

9. Frédéric, S.H.; Donzé, V.; Daudeville, L. Discrete element modeling of concrete submitted to dynamic loading at high strain rates. Comput. Struct. 2004, 82, 2509-2524.

10. Tan, Y.; Yang, D.; Sheng, Y. Discrete element method (DEM) modeling of fracture and damage in the machining process of polycrystalline SiC. J. Eur. Ceram. Soc. 2009, 29, 1029-1037. [CrossRef]

11. Itasca Consulting Group Inc. PFC2D (Particle Flow Code in 2-Dimensions); Version 3.10; Itasca Consulting Group Inc.: Minneapolis, MN, USA, 2004.

12. Ostanin, I.; Ballarini, R.; Potyond, D.; Dumitric, T. A distinct element method for large scale simulations of carbon nanotube assemblies. J. Mech. Phys. Solids 2013, 61, 762-782. [CrossRef]

13. Benvenuti, L.; Kloss, C.; Pirker, S. Identification of DEM simulation parameters by Artificial Neural Networks and bulk experiments. Powder Technol. 2016, 291, 456-465. [CrossRef]

14. Horabik, J.; Molenda, M. Parameters and contact models for DEM simulations of agricultural granular materials: A review. Biosyst. Eng. 2016, 147, 206-225. [CrossRef]

15. Rajeev, S. Discrete Element Modeling of Silicon Nitride Ceramics. Ph.D. Thesis, University of Texas, Austin, TX, USA, 2009.

16. Field, J. The mechanical and strength properties of diamond. Rep. Prog. Phys. Phys. Soc. 2012, 75, 126-135. [CrossRef] [PubMed]

17. Oliveira, L.J.; Guerold, S.B.; Marcello, F. Processing and characterization of impregnated diamond cutting tools using a ferrous metal matrix. Int. J. Refract. Metals Hard Mater. 2007, 25, 328-335. [CrossRef]

18. Zhao, X.J.; Duan, L. A Review of the Diamond Retention Capacity of Metal Bond Matrices. Metals 2018, 8, 307. [CrossRef]

(c) 2018 by the authors. Licensee MDPI, Basel, Switzerland. This article is an open access article distributed under the terms and conditions of the Creative Commons Attribution (CC BY) license (http:/ / creativecommons.org/licenses/by/4.0/). 